\title{
Effectiveness of Current Treatments for Covid-19
}

\author{
Abidur Rahman \\ Wayne State University \\ College of Engineering \\ 42 W Warren Ave, Detroit, MI 48202 \\ aabidurrahman95@gmail.com
}

\begin{abstract}
Severe Acute Respiratory Syndrome Coronavirus 2(SARS-CoV-2) is the virus that caused COVID-19 around the world. The disease starts off as a flu-like symptom and then eventually spreads in the human body.Infections are easily transmitted from human to human which makes it more severe among individuals. SARS-CoV-2 virus is in the same family of viruses SARS and MERS.As of today, there is no approved vaccine that can cure COVID-19. However, potential treatments showing promising improvement results among affected COVID-19 patients. In this review, the effectiveness of the current treatments for COVID-19 has been explored.
\end{abstract}

\section{Keywords}

SARS-CoV-2, Covid-19, Antiviral Drugs, Immunomodulators, Neutralizing Antibody Therapy, Cell Therapy, Current Vaccine Stage

\section{Introduction}

The novel COVID-19 is respiratory disease that is caused by SARS-CoV-2(severe acute respiratory syndrome coronavirus 2) virus. It is also an infectious disease which was first identified in Wuhan, China in december 2019. Before 2002, coronaviruses only caused common flu in humans[1]. However, it was not until the outbreak of severe acute respiratory syndrome(SARS) of 2003 in Guangdong province, southern China, SARS was classified as a highly infectious disease[6]. The outbreak of 2003 was caused by pneumonia with fever and mild respiratory symptoms among people, but within a few days it rapidly transmitted among person to person[4]. Almost after 10 years, A man with severe pneumonia was admitted to a hospital in Jeddah, Saudi Arabia[3]. After further clinical studies of the patient, it was reported that the pneumonia was related to coronaviruses and eventually this new virus was named as MERS-CoV[2].

Fast forward to December 2019, A 41 year old patient with severe respiratory syndrome was admitted to the Central Hospital of Wuhan, China. RNA sequencing data identified a new RNA virus which was at first named as 2019-nCoV. Additionally, phylogenetic analysis also revealed that this new virus is related to the family of SARS coronaviruses. Soon after, due to its severity of transmission it was then named as SARS-CoV-2[5]. As of today, it has affected more than 46 million people in more than 150 countries.

Angiotensin-converting enzyme 2(ACE-2) is a protein that acts as a receptor for Covid-19. When 
an infected person sneezes, the droplet of their sneezing carrying the virus can travel through your nose or mouth to your body. The virus uses the receptor as a pathway to enter the human body and eventually cause damage to your throat and lung. The virus then travels from your trachea to bronchi to bronchioles and eventually to the alveoli. Immune system attacks viruses to keep you healthy. However, if your immune system is weak it makes it easier for the virus to infect your body[7].

Current available treatments depend on a patient's severity of COVID-19.These treatments fall under antiviral drugs, immunomodulators,neutralizing antibody therapies,cell therapy, and gene therapy. The effectiveness of these treatments is being discussed in this review.

\section{Antiviral Drugs}

\subsection{Remdesivir}

Remdesivir is an RNA-dependent RNA polymerase (RdRP) inhibitor which was used during the 2014 ebola outbreak among affected patients.Additionally, it was used to treat hepatitis $\mathrm{C}$ and respiratory syncytial virus. On May 1, 2020, The U.S. Food and Drug Administration (FDA) has granted permission to use remdesivir to treat COVID-19 patients.

Remdesivir achieves its antiviral effects through inhibiting viral nucleic acid synthesis. SARSCoV-2 is a single-stranded RNA virus, and the genomic replication process of RNA viruses is dominated by RdRP. After the virus invades the host cell and the host cell protein synthesis system is used for the translation of RdRP [8]. Remdesivir interrupts the production of the virus. Covid-19 has genomes that are made of ribonucleic acid(RNA). Remdesivir interferes with the virus enzyme that helps the virus to multiply.

A recent study in italy done on covid-19 patients under mechanical ventilation has shown a significant increase in survival rate. 51 patients were considered in the clinical trials. Out of those 25 were given remdesivir and other 26 were not given remdesivir. Among the 25 patients with remdesivir, treatment initiation and symptom onset was 18 days. 20 patients completed 10 days treatment while 5 died 5 days after starting treatment with remdesivir. At the end, out of those 51 patients, 38 patients had died while 9 patients had been discharged from hospital. However the survival rate among patients with remdesivir was much higher[9]. 


\section{Table 1.}

Demographic and clinical characteristics of the patients

\begin{tabular}{|c|c|c|c|c|}
\hline Characteristics & Total $(N=51)$ & Remdesivir group $(N=25)$ & No remdesivir group $(N=26)$ & $P$ \\
\hline Male sex, $n(\%)$ & $47(92.2)$ & $23(92)$ & $24(92.3)$ & $>0.999$ \\
\hline Median (IQR) age (years) & $67(59-75.5)$ & $64(57-75)$ & $70(63.3-76)$ & 0.313 \\
\hline Interval between symptom onset and ICU admission, median (IQR) (days) & $10(8-12)$ & $11(8-13)$ & $9(8-11)$ & 0.197 \\
\hline \multicolumn{5}{|l|}{ Comorbidities, $n(\%)$} \\
\hline ischaemic heart disease & $7(13.7)$ & $3(12)$ & $4(15.4)$ & $>0.999$ \\
\hline congestive heart failure & $4(7.8)$ & $0(0)$ & $4(15.4)$ & 0.110 \\
\hline COPD & $3(5.9)$ & $0(0)$ & $3(11.5)$ & 0.235 \\
\hline diabetes mellitus & $7(13.7)$ & $3(12)$ & $4(15.4)$ & $>0.999$ \\
\hline chronic kidney disease & $4(7.8)$ & $2(8)$ & $2(7.7)$ & $>0.999$ \\
\hline hypertension & $28(54.9)$ & $14(56)$ & $14(53.8)$ & 0.877 \\
\hline Median (IQR) Charlson Comorbidity Index & $3(1-4)$ & $2(1-3)$ & $3(3-4)$ & 0.131 \\
\hline \multicolumn{5}{|l|}{ Laboratory values } \\
\hline mean $=\mathrm{SD} W B C / \mathrm{mm}^{3}$ & $9246 \pm 3500$ & $9172 \pm 3203$ & $9318 \pm 3826$ & 0.883 \\
\hline mean $=\mathrm{SD}$ neutrophils $/ \mathrm{mm}^{3}$ & $8040 \pm 3342$ & $7902=3224$ & $8173=3511$ & 0.775 \\
\hline median (IQR) lymphocytes $/ \mathrm{mm}^{3}$ & $600(400-900)$ & $600(500-830)$ & $550(300-900)$ & 0.263 \\
\hline median (IQR) platelets $\times 10^{3} / \mathrm{mm}^{3}$ & $190(153-245)$ & $192(162-242)$ & $184(145-247)$ & 0.578 \\
\hline median (IQR) creatinine ( $\mathrm{mg} / \mathrm{dL}$ ) & $1.04(0.86-1.45)$ & $0.97(0.89-1.24)$ & $1.11(0.85-1.57)$ & 0.468 \\
\hline median (IQR) ALT (U/L) & $45(32.5-65.5)$ & $45(26-67)$ & $45(37.3-61.8)$ & 0.402 \\
\hline median $(\mathrm{IQR}) \mathrm{AST}(\mathrm{U} / \mathrm{L})$ & $34(25.5-53)$ & $34(23-55)$ & $33.5(27.5-43.8)$ & 0.671 \\
\hline median (IQR) total bilirubin (mg/dL) & $0.9(0.65-1.25)$ & $0.9(0.7-1.2)$ & $0.8(0.6-1.28)$ & 0.564 \\
\hline median (IQR) LDH (U/L) & $473(387-559)$ & $450(342-510)$ & $542(416-559)$ & 0.070 \\
\hline mean $=\operatorname{SD~CRP~}(\mathrm{mg} / \mathrm{dL})$ & $20.5 \pm 11.8$ & $20.9=13.8$ & $20.2 \pm 9.7$ & 0.833 \\
\hline Median (IQR) SOFA score at admission & $5(4-6)$ & $4(3-5)$ & $5(4-6)$ & 0.037 \\
\hline $\mathrm{CRRT}, n(\%)$ & $25(49)$ & $10(40)$ & $15(57.7)$ & 0.206 \\
\hline \multicolumn{5}{|l|}{ Concomitant therapies, $n(\%)$} \\
\hline hydroxychloroquine & $33(64.7)$ & $17(68)$ & $16(61.5)$ & 0.771 \\
\hline lopinavir/ritonavir & $29(56.9)$ & $15(60)$ & $14(53.8)$ & 0.657 \\
\hline tocilizumab & $9(17.6)$ & $7(28)$ & $2(7.7)$ & 0.075 \\
\hline
\end{tabular}

Normally distributed continuous data are reported as mean $=\mathrm{SD}$. Non-normally distributed continuous data are reported as median and IQR.

Figure 1: Characterististics of Patients[9]

Another study also showed significant decrease in the time of recovery among patients with remdesivir treatment who had lower respiratory tract infection. A total of 1062 patients went to a randomization clinical trial. Out of those patients, 541 were given remdesivir while 521 patients received no remdesivir for the randomization experiment[10]. 


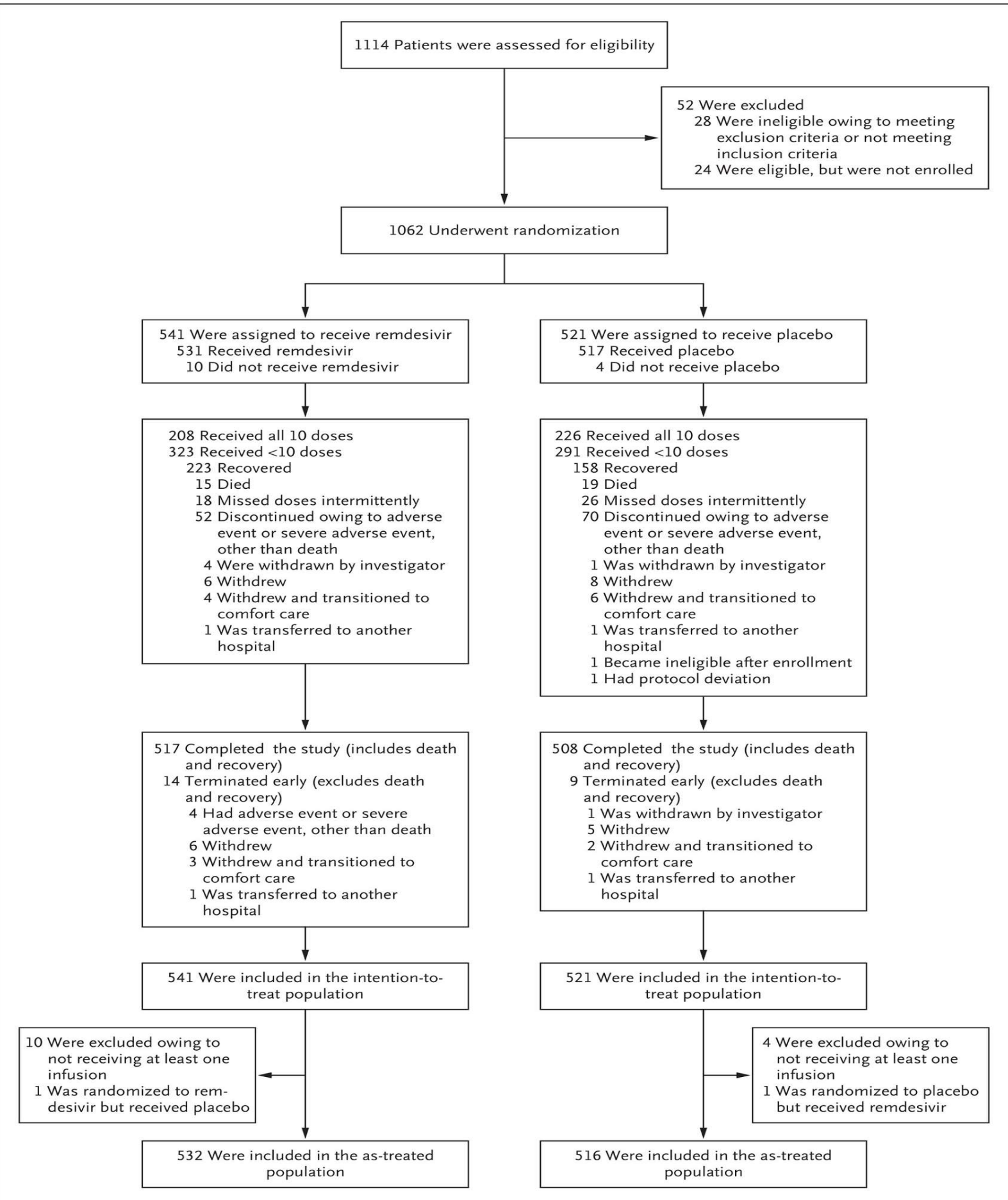

Figure 2: Clinical Trial [10]

The clinical trials found out that people in remdesivir had a median 10 days shorter time recovery compared to non-remdesivir group. In the severe cases of Covid-19 the median time recovery was 11 days compared to 18 days with non-remdesivir group. Mortality rate which was done through Kaplan-Meier estimation found out that mortality rate was $6.7 \%$ among 15 days 
recovery patients in remdesivir group. While non-remdesivir group had $11.9 \%$ mortality rate[10].

\begin{tabular}{|c|c|c|c|c|c|c|c|c|c|c|}
\hline & \multirow[b]{3}{*}{$\begin{array}{l}\text { Remdesivir } \\
\text { ( } \mathrm{N}=541)\end{array}$} & \multirow[b]{3}{*}{$\begin{array}{l}\text { Placebo } \\
(\mathrm{N}=521)\end{array}$} & \multicolumn{8}{|c|}{ Ordinal Score at Baseline } \\
\hline & & & \multicolumn{2}{|c|}{4} & \multicolumn{2}{|c|}{5} & \multicolumn{2}{|c|}{6} & \multicolumn{2}{|c|}{7} \\
\hline & & & $\begin{array}{l}\text { Remdesivir } \\
(\mathrm{N}=75)\end{array}$ & $\begin{array}{l}\text { Placebo } \\
(\mathrm{N}=63)\end{array}$ & $\begin{array}{l}\text { Remdesivir } \\
(\mathrm{N}=232)\end{array}$ & $\begin{array}{l}\text { Placebo } \\
(\mathrm{N}=203)\end{array}$ & $\begin{array}{l}\text { Remdesivir } \\
(\mathrm{N}=95)\end{array}$ & $\begin{array}{l}\text { Placebo } \\
(\mathrm{N}=98)\end{array}$ & $\begin{array}{l}\text { Remdesivir } \\
(\mathrm{N}=131)\end{array}$ & $\begin{array}{l}\text { Placebo } \\
(\mathrm{N}=154)\end{array}$ \\
\hline \multicolumn{11}{|l|}{ Recovery } \\
\hline No. of recoveries & 399 & 352 & 73 & 58 & 206 & 156 & 57 & 61 & 63 & 77 \\
\hline $\begin{array}{l}\text { Median time to recovery } \\
(95 \% \mathrm{CI}) \text { - days }\end{array}$ & $10(9-11)$ & $15(13-18)$ & $5(4-6)$ & $6(4-7)$ & $7(6-8)$ & $9(7-10)$ & $15(10-27)$ & $20(14-26)$ & 29 (24-NE) & 28 (24-NE) \\
\hline Rate ratio $(95 \% \mathrm{Cl}) \uparrow$ & \multicolumn{2}{|c|}{$1.29(1.12-1.49[P<0.001])$} & \multicolumn{2}{|c|}{$1.29(0.91-1.83)$} & \multicolumn{2}{|c|}{$1.45(1.18-1.79)$} & \multicolumn{2}{|c|}{$1.09(0.76-1.57)$} & \multicolumn{2}{|c|}{$0.98(0.70-1.36)$} \\
\hline \multicolumn{11}{|l|}{ Mortality through day $14 \frac{\zeta}{?}$} \\
\hline $\begin{array}{l}\text { Hazard ratio for data through day } 15 \\
\quad(95 \% \mathrm{CI})\end{array}$ & \multicolumn{2}{|c|}{$0.55(0.36-0.83)$} & \multicolumn{2}{|c|}{$0.42(0.04-4.67)$} & \multicolumn{2}{|c|}{$0.28(0.12-0.66)$} & \multicolumn{2}{|c|}{$0.82(0.40-1.69)$} & \multicolumn{2}{|c|}{$0.76(0.39-1.50)$} \\
\hline No. of deaths by day 15 & 35 & 61 & 1 & 2 & 7 & 21 & 13 & 17 & 14 & 21 \\
\hline $\begin{array}{l}\text { Kaplan-Meier estimate of mortality } \\
\text { by day } 15-\%(95 \% \mathrm{CI})\end{array}$ & $\begin{array}{c}6.7 \\
(4.8-9.2)\end{array}$ & $\begin{array}{c}11.9 \\
(9.4-15.0)\end{array}$ & $\begin{array}{c}1.3 \\
(0.2-9.1)\end{array}$ & $\begin{array}{c}3.2 \\
(0.8-12.1)\end{array}$ & $\begin{array}{c}3.1 \\
(1.5-6.4)\end{array}$ & $\begin{array}{c}10.5 \\
(7.0-15.7)\end{array}$ & $\begin{array}{c}14.2 \\
(8.5-23.2)\end{array}$ & $\begin{array}{c}17.3 \\
(11.2-26.4)\end{array}$ & $\begin{array}{c}10.9 \\
(6.6-17.6)\end{array}$ & $\begin{array}{c}13.8 \\
(9.2-20.4)\end{array}$ \\
\hline \multicolumn{11}{|l|}{ Mortality over entire study period $\$$} \\
\hline Hazard ratio $(95 \% \mathrm{Cl})$ & \multicolumn{2}{|c|}{$0.73(0.52-1.03)$} & \multicolumn{2}{|c|}{$0.82(0.17-4.07)$} & \multicolumn{2}{|c|}{$0.30(0.14-0.64)$} & \multicolumn{2}{|c|}{$1.02(0.54-1.91)$} & \multicolumn{2}{|c|}{$1.13(0.67-1.89)$} \\
\hline No. of deaths by day 29 & 59 & 77 & 3 & 3 & 9 & 25 & 19 & 20 & 28 & 29 \\
\hline $\begin{array}{l}\text { Kaplan-Meier estimate of mortality } \\
\text { by day } 29-\%(95 \% \mathrm{CI})\end{array}$ & $\begin{array}{c}11.4 \\
(9.0-14.5)\end{array}$ & $\begin{array}{c}15.2 \\
(12.3-18.6)\end{array}$ & $\begin{array}{c}4.1 \\
(1.3-12.1)\end{array}$ & $\begin{array}{c}4.8 \\
(1.6-14.3)\end{array}$ & $\begin{array}{c}4.0 \\
(2.1-7.5)\end{array}$ & $\begin{array}{c}12.7 \\
(8.8-18.3)\end{array}$ & $\begin{array}{c}21.2 \\
(14.0-31.2)\end{array}$ & $\begin{array}{c}20.4 \\
(13.7-29.8)\end{array}$ & $\begin{array}{c}21.9 \\
(15.7-30.1)\end{array}$ & $\begin{array}{c}19.3 \\
(13.8-26.5)\end{array}$ \\
\hline \multicolumn{11}{|l|}{$\begin{array}{l}\text { Ordinal score at day } 15( \pm 2 \text { days })- \\
\text { no. }(\%) \int\end{array}$} \\
\hline 1 & $157(29.0)$ & $115(22.1)$ & $38(50.7)$ & $28(44.4)$ & $90(38.8)$ & $62(30.5)$ & $18(18.9)$ & $14(14.3)$ & $11(8.4)$ & $11(7.1)$ \\
\hline 2 & $117(21.6)$ & $102(19.6)$ & $20(26.7)$ & $15(23.8)$ & $70(30.2)$ & $58(28.6)$ & $22(23.2)$ & $19(19.4)$ & $5(3.8)$ & $10(6.5)$ \\
\hline 3 & $14(2.6)$ & $8(1.5)$ & $8(10.7)$ & $4(6.3)$ & $6(2.6)$ & $4(2.0)$ & 0 & 0 & 0 & 0 \\
\hline 4 & $38(7.0)$ & $33(6.3)$ & $3(4.0)$ & $7(11.1)$ & $17(7.3)$ & $13(6.4)$ & $12(12.6)$ & $4(4.1)$ & $6(4.6)$ & $9(5.8)$ \\
\hline 5 & $58(10.7)$ & $60(11.5)$ & $3(4.0)$ & $5(7.9)$ & $25(10.8)$ & $18(8.9)$ & $2(2.1)$ & $14(14.3)$ & $28(21.4)$ & $23(14.9)$ \\
\hline 6 & $28(5.2)$ & $24(4.6)$ & $1(1.3)$ & 0 & $5(2.2)$ & $7(3.4)$ & $12(12.6)$ & $11(11.2)$ & $10(7.6)$ & $6(3.9)$ \\
\hline 7 & $95(17.6)$ & $121(23.2)$ & $1(1.3)$ & $3(4.8)$ & $13(5.6)$ & $21(10.3)$ & $16(16.8)$ & $20(20.4)$ & $57(43.5)$ & $74(48.1)$ \\
\hline 8 & $34(6.3)$ & 58 (11.1) & $1(1.3)$ & $1(1.6)$ & $6(2.6)$ & $20(9.9)$ & $13(13.7)$ & $16(16.3)$ & $14(10.7)$ & $21(13.6)$ \\
\hline Odds ratio $(95 \% \mathrm{CI})$ & \multicolumn{2}{|c|}{$1.5(1.2-1.9)$} & \multicolumn{2}{|c|}{$1.5(0.8-2.7)$} & \multicolumn{2}{|c|}{$1.6(1.2-2.3)$} & \multicolumn{2}{|c|}{$1.4(0.9-2.3)$} & \multicolumn{2}{|c|}{$1.2(0.8-1.9)$} \\
\hline
\end{tabular}

Figure 3: Outcome of Patients [10]

However, despite having a mortality rate with remdesivir, health professionals do not recommend extensive usage of remdesivir because only an antiviral drug is not sufficient for every Covid-19 patient. 


\subsection{Hydroxychloroquine}

Hydroxychloroquine is an aminoquinoline drug that was invented 7 decades ago. It was an effective drug that was used in malaria and rheumatic diseases. On march 30, 2020 FDA(Food and Drug Administration) of the United States has granted the permission to use the drug on Covid-19 patients in non-clinical trials. As the guidelines suggested, the usage of the drug was only permissible to Covid-19 patients with signs of pneumonia. Despite the guidelines, it is being used extensively in many countries in the world. A recent study suggested that hydroxychloroquine is a safer and more effective antiviral than chloroquine. An observational study conducted at Columbia University Irving Medical Center (CUIMC) has shown the efficacy and correlation of hydroxychloroquine to death rate among Covid-19 patients. For the study 1376 patients were observed. Out of those patients, 811 patients were treated with hydroxychloroquine while others did not receive it. From the outcome of the study it turned out that hydroxychloroquine patients were ill than those who did not receive it. However, propensity score matching results did not show any major correlation in death rate even though the drug worsened the condition of Covid-19 patients [11].

Table 2. Associations between Hydroxychloroquine Use and the Composite End Point of Intubation or Death in the Crude Analysis, Multivariable Analysis, and Propensity-Score Analyses.

\section{Analysis} Intubation or Death

No. of events/no. of patients at risk (\%)

Hydroxychloroquine

No hydroxychloroquine

Crude analysis - hazard ratio $(95 \% \mathrm{Cl})$

Multivariable analysis - hazard ratio $(95 \% \mathrm{CI})$ *

Propensity-score analyses - hazard ratio $(95 \% \mathrm{Cl})$

With inverse probability weighting $\dagger$

With matching $\%$

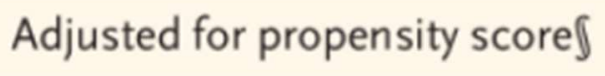

$1.04(0.82-1.32)$

$0.98(0.73-1.31)$

$262 / 811(32.3)$

$84 / 565$ (14.9)

2.37 (1.84-3.02)

$1.00(0.76-1.32)$

$0.97(0.74-1.28)$

Figure 4: Hydroxychloroquine Results [11] 


\subsection{Lopinavir/Ritonavir}

Lopinavir is a protease inhibitor, a class of medications, that has been used in the treatment of HIV patients. Usually lopinavir is combined with ritonavir, another protease inhibitor to increase the half-life of lopinavir. Additionally, the combination of lopinavir and ritonavir also increase the effectiveness of the medication in the body. However, it is not a cure for HIV, but reduces the development of HIV among patients.

A two months study at a hospital in Wuhan, China reported that lopinavir-ritonavir treatment alongside with standard care did not show drastic change in improvement and mortality rate of severely Covid-19 patients. However, the intention-to-treat analysis did show a little improvement in a median recovery time of 15 days among lopinavir/ritonavir patients vs 16 days among other patients. But, the mortality rate in the trail was $22.1 \%$, which was lower before the trial. The study also suggests one possibility for the high mortality is due to the treatment within 12 days and the treatment after 12 days [12].

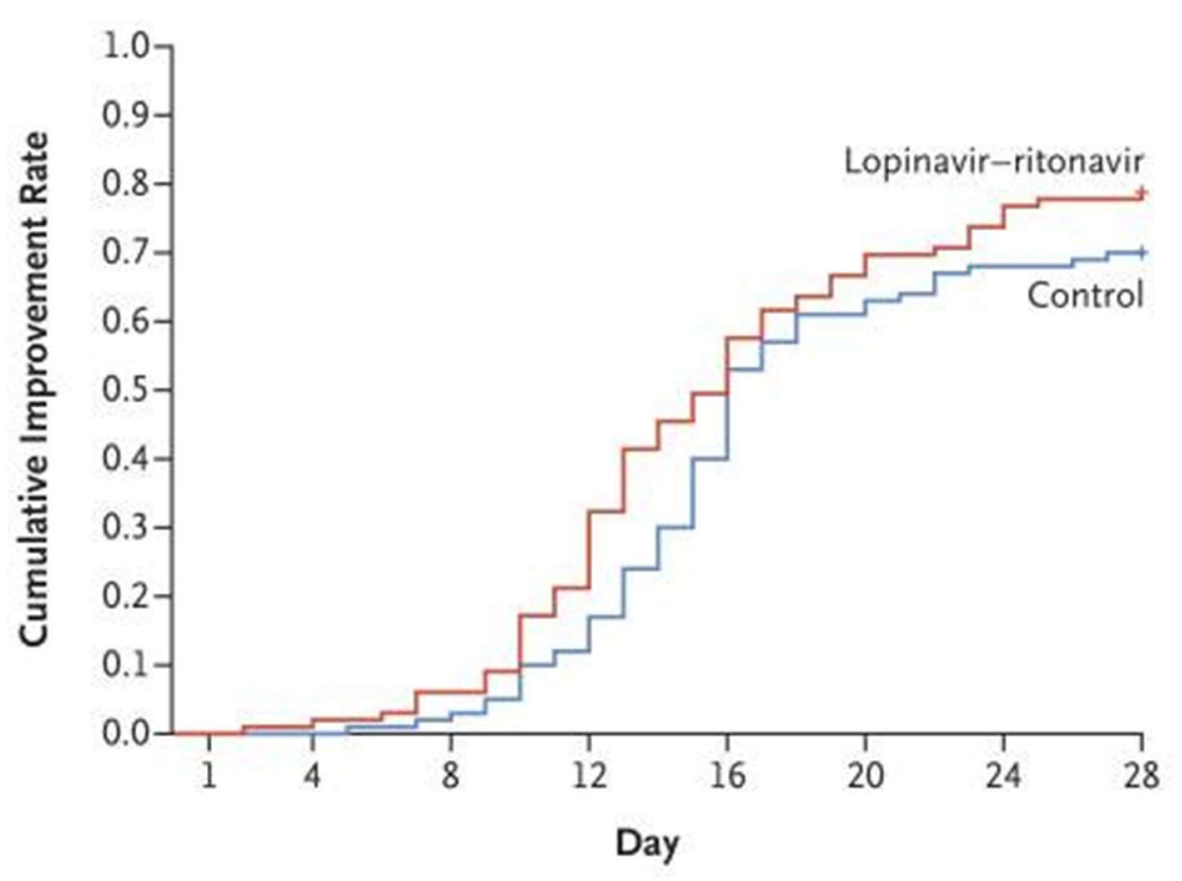

No. at Risk

$\begin{array}{lrrrrrrrr}\text { Lopinavir-ritonavir } & 99 & 98 & 93 & 78 & 50 & 33 & 26 & 22 \\ \text { Control } & 100 & 100 & 98 & 88 & 60 & 39 & 32 & 30\end{array}$

Figure 5: Time to Clinical Improvement [12]

\subsection{Ivermectin}

Ivermectin is FDA-approved drug that has been used in parasitic infections among humans and animals. Studies also suggested it was effective in RNA viruses such as Zika, dengue, yellow fever. Initially it was used only on animals. However, in 2015 its usage in humans was confirmed after William C. Campbell and Satoshi Omura developed the drug for human use [13]. 
However, FDA did not approve ivermectin as a treatment for Covid-19 patients. Despite, in laboratory settings it has shown to inhibit the replication of Sars-Cov-2 virus [14].

\subsection{Favipiravir}

Favipiravir (FPV) is an RNA-dependent RNA polymerase inhibitor. It was shown effective treatment in influenza and Ebola virus [15].A report has shown favipiravir is effective in reducing Covid-19 patients[16].However, in a recent study, severely ill Covid-19 patients did not show drastic improvement in their health. While moderate covid-19 patients did show improvement in their CT scan images. FPV was given orally within a period of 14 days. The CT scan was conducted on day 4,9, and 14 and covid-19 infection were detected through a quantitative polymerase chain reaction(qPCR) method. After the treatment four patients in the FPV group were reported to have a negative effect in their health compared to less than 25 patients in the non-FPV group. Additionally, two patients had diarrhea and one had liver injury in the FPV group. While five patients had diarrhea, five with vomiting in the non-FPV group [17].

Statistics of adverse reactions after medication.

\begin{tabular}{llll}
\hline \multicolumn{1}{c}{ Characteristic } & \multicolumn{3}{c}{ Treatment } \\
\cline { 2 - 4 } & FPV $(\boldsymbol{N}=\mathbf{3 5})$ & LPV/RTV $(\boldsymbol{N = 4 5})$ & $\boldsymbol{P}$ value \\
\hline Total number of adverse reactions & $4(11.43 \%)$ & $25(55.56 \%)$ & $<0.001$ \\
Diarrhea & $2(5.71 \%)$ & $5(11.11 \%)$ & 0.46 \\
Vomiting & $0(0 \%)$ & $5(11.11 \%)$ & 0.06 \\
Nausea & $0(0 \%)$ & $6(13.33 \%)$ & 0.03 \\
Rash & $0(0 \%)$ & $4(8.89 \%)$ & 0.13 \\
Liver and kidney injury & $1(2.86 \%)$ & $3(6.67 \%)$ & 0.63 \\
Others & $1(2.86 \%)$ & $2(4.44 \%)$ & 1.00 \\
\hline
\end{tabular}

Figure 6: Reactions results after medications [17]

\subsection{Ribavirin}

Ribavirin is a synthetic guanosine nucleoside that interferes with the synthesis of viral RNA and DNA viruses. It is used to treat hepatitis $\mathrm{C}$ and hemorrhagic fevers. A recent study compared the efficacy of ribavirin between supportive therapy and ribavirin therapy in severely ill Covid-19 patients with pneumonia. The experiment showed a lower mortality rate in Ribavirin group compared to non-Ribavirin group. For the experiment a total of 115 patients were analyzed. 44 
received ribavirin treatment while 71 did not. Statistical analysis showed that overall mortality rate was $17.1 \%$ in the ribavirin group while in the non-ribavirin group mortality rate was $24.6 \%$. When ribavirin was used during the MERS-CoV and SARS-CoV outbreak, Anaemia was a common issue after the treatment. However, in the current study done with Covid-19 patients there was no sign of anaemia after Ribavirin treatment [19].

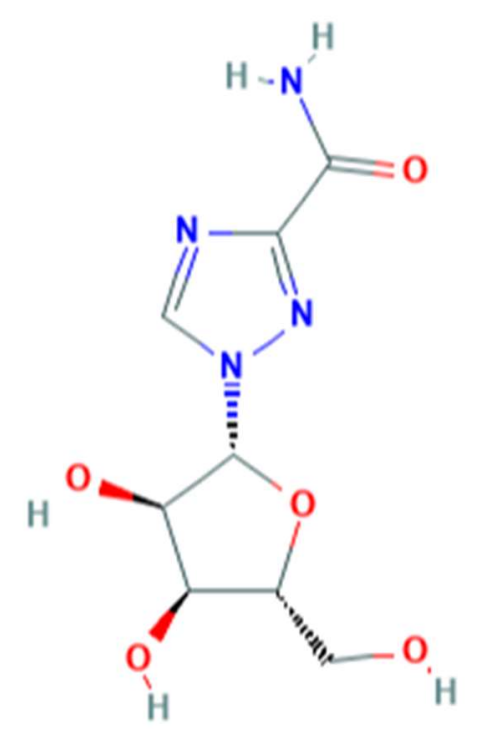

Figure 6: Chemical structure of ribavirin [18]

\section{Immunomodulators}

\subsection{Dexamethasone}

Corticosteroids are a class of drug that lowers inflammation and reduces immune activity in the human body. Treating infections with corticosteroids is still a controversy among health professionals. During the pandemic, data on the effectiveness of the usage of corticosteroids on Covid-19 patients were limited. A recent study also showed that there is no clinical data that is showing promising results from corticosteroids. Additionally, the study also reported using corticosteroids on severe Covid-19 patients does not reduce the mortality rate among Covid-19 patients [20].

However, another study suggested that dexamethasone, a type of corticosteroids, did reduce mortality rate among Covid019 patients. In the controlled experiment a total of 2104 patients received dexamethasone while 4321 received usual clinical care. After 28 days, mortality rate was $22.9 \%$ in the dexamethasone group. Meanwhile non-dexamethasone group had a mortality rate of $25.7 \%$. Additionally, in dexamethasone group death rate was lower than in usual clinical care patients with mechanical ventilation and also in patients who received oxygen without invasive mechanical ventilation. But those who did not receive respiratory support, did not show any effect of dexamethasone. 


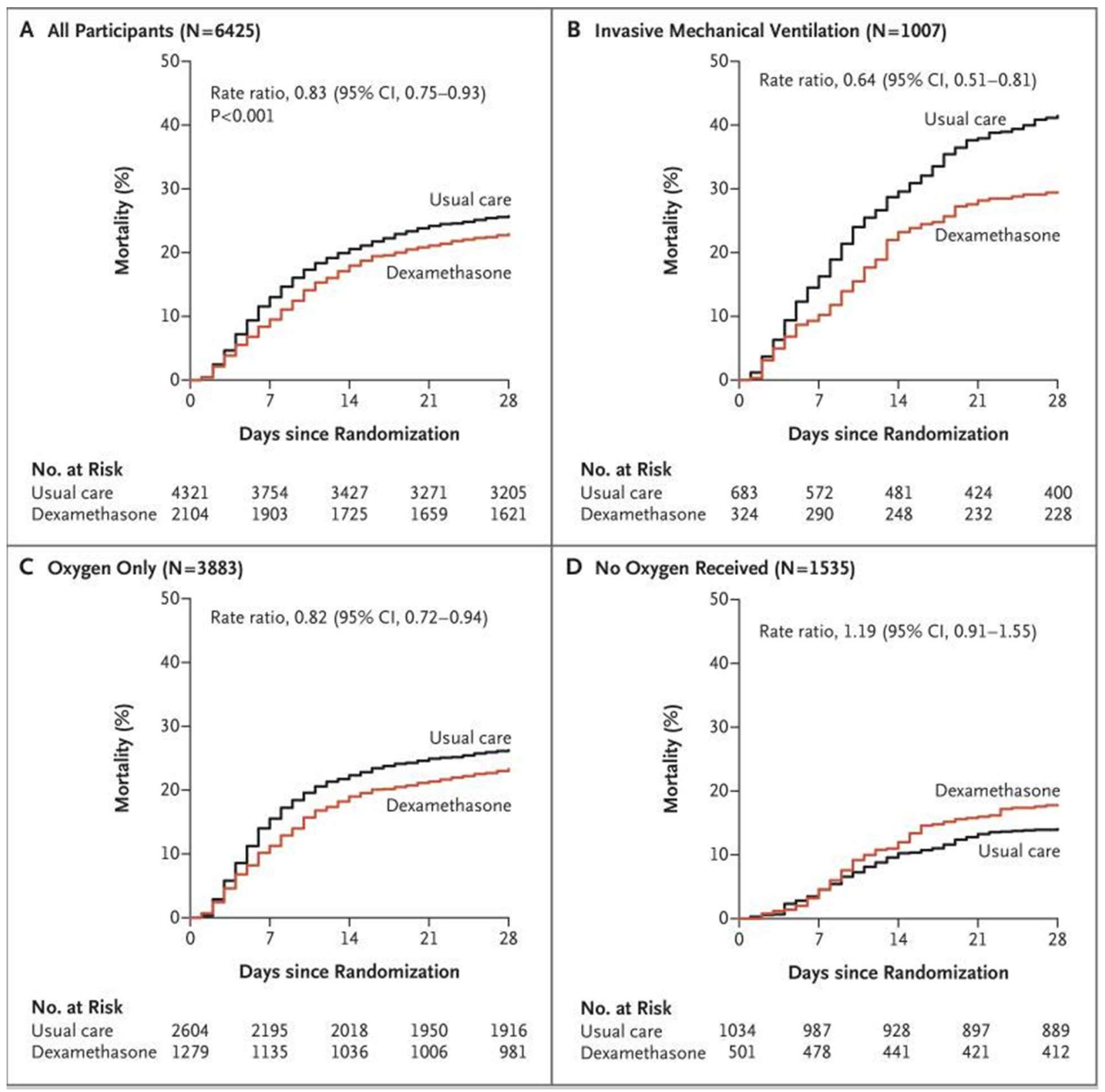

Figure 7: Mortality rate among patients at 28 days.[21]

Also, patients 10 years younger who received invasive mechanical ventilation than those who received respiratory support in the trails. Besides, patients with longer duration of symptoms had lower mortality rate [21].

\subsection{Interferon Beta-1a}

Interferons are a family of cytokines which has a potential efficacy in the treatment of Covid-19 patients. Among other interferons, Interferon Beta-1a shows promising results due to the known pharmacological results [22]. Interferons (IFN) has previously been used in the treatment of SARS and MERS outbreak. Studies also showed antiviral effects of IFN on SARS-CoV and 
MERS-CoV. By activating ISGs (interferon-stimulated genes), the antiviral effects of interferon are achieved. In a recent study on the efficacy of interferon-beta- $1 \mathrm{a}, 81$ patients went through a trial. Among those 42 were in the IFN group while 39 were assigned in the non-IFN group. Adding IFN to the clinical trial did not change the time to reach clinical response. However, IFN did lower the mortality rate and discharge rate among the patients. Patients who received IFN earlier also showed benefit from the treatment despite having injection-related side effects which were tolerable [28].

Findings based on the six-category scale at days $0,7,14$, and 28

\begin{tabular}{|c|c|c|c|c|}
\hline \multirow{2}{*}{\multicolumn{2}{|c|}{ Parameter }} & \multicolumn{2}{|c|}{ Value(s) $[$ no. $(\%)]$ for: } & \multirow[t]{2}{*}{ OR (if calculated) } \\
\hline & & IFN group $(n=42)$ & Control group $(n=39)$ & \\
\hline \multicolumn{5}{|l|}{ Day 0} \\
\hline \multicolumn{5}{|c|}{ 1-Discharge } \\
\hline & 2-Hospital admission not requiring supplemental oxygen & $1(2.38)$ & 0 & \\
\hline & 3-Hospital admission, requiring supplemental oxygen & $29(69.04)$ & $27(69.23)$ & \\
\hline & 4-Hospital admission, requiring high-flow nasal cannula or noninvasive mechanical ventilation & $3(7.14)$ & $1(2.56)$ & \\
\hline & 5-Hospital admission, requiring invasive mechanical ventilation & $9(21.42)$ & $11(28.20)$ & \\
\hline & \multicolumn{4}{|l|}{ 6-Death } \\
\hline \multicolumn{5}{|l|}{ Day 7} \\
\hline & 1-Discharge & $8(19.04)$ & $11(28.20)$ & $0.60(0.21-1.69)$ \\
\hline & 2-Hospital admission not requiring supplemental oxygen & $2(4.76)$ & 0 & \\
\hline & 3-Hospital admission, requiring supplemental oxygen & $21(50.00)$ & $12(30.76)$ & \\
\hline & 4-Hospital admission, requiring high-flow nasal cannula or noninvasive mechanical ventilation & $1(2.38)$ & 0 & \\
\hline & 5-Hospital admission, requiring invasive mechanical ventilation & $10(23.80)$ & $6(15.38)$ & \\
\hline & 6-Death & 0 & $10(25.64)$ & \\
\hline \multicolumn{5}{|l|}{ Day 14} \\
\hline & 1-Discharge & $28(66.66)$ & $17(43.58)$ & $2.5(1.05-6.37)$ \\
\hline & 2-Hospital admission not requiring supplemental oxygen & $1(2.38)$ & 0 & \\
\hline & 3-Hospital admission, requiring supplemental oxygen & $5(11.90)$ & $6(15.38)$ & \\
\hline & 4-Hospital admission, requiring high-flow nasal cannula or noninvasive mechanical ventilation & $1(2.38)$ & 0 & \\
\hline & 5-Hospital admission, requiring invasive mechanical ventilation & $3(7.14)$ & $2(5.12)$ & \\
\hline & 6-Death & $4(9.52)$ & $14(35.89)$ & \\
\hline \multicolumn{5}{|l|}{ Day 28} \\
\hline & 1-Discharge & $31(73.80)$ & $23(58.97)$ & $1.96(0.76-5.01)$ \\
\hline & 2-Hospital admission not requiring supplemental oxygen & $2(4.76)$ & 0 & \\
\hline & 3-Hospital admission, requiring supplemental oxygen & $1(2.38)$ & 0 & \\
\hline & 4-Hospital admission, requiring high-flow nasal cannula or noninvasive mechanical ventilation & 0 & 0 & \\
\hline & 5-Hospital admission, requiring invasive mechanical ventilation & 0 & $1(2.56)$ & \\
\hline & 6-Death & $8(19.04)$ & $15(38.46)$ & \\
\hline
\end{tabular}

Figure 8: Patients statistics on day $0,7,14$, and 28 of IFN and non-IFN group [28]

\section{Neutralizing Antibody Therapies}

\subsection{LY-CoV555(Bamlanivimab)}

Ly-CoV555 was recently approved by FDA for emergency use.LY-CoV555 is a monoclonal antibody therapy that can be a potential treatment for mild to moderate Covid-19 patients. 
Monoclonal antibodies are laboratory made proteins to fight viruses in a person's immune system. A recent study published in the New England Journal of Medicine showed the efficacy of LY-CoV555 on Covid-19 patients. In the clinical trial, 317 patients were assigned to LYCoV55 while 150 patients were put in placebo.LY-CoV555 patients were given dosages in 700, 2800 , and $7000 \mathrm{mg}$ respectively. At day 11, viral load was lower in LY-CoV55 group than the placebo group. However, physicians also saying that decrease in viral load is not the definitive indicator overall improvement in hospitalization. But the effect of LY-CoV55 on patients at a earlier time period of the treatment cycle did show a little treatment effect. What is speculative is that whether reverse transcription polymerase chain reaction (RT-PCR) test results are accurate or not. Although data associated with patient's symptom were consistent which showed a reduction in the severity of symptom on day 2 in LY-CoV555 group. Additionally, safety profile was relatively equal in both LY-CoV555 and placebo group which indicates that the treatment is safe [23].

\begin{tabular}{|c|c|c|c|}
\hline Variable & $\begin{array}{c}\text { LY-CoV555 } \\
(\mathrm{N}=309)\end{array}$ & $\begin{array}{l}\text { Placebo } \\
(\mathrm{N}=143)\end{array}$ & $\begin{array}{c}\text { Difference } \\
\text { (95\% CI) }\end{array}$ \\
\hline \multicolumn{4}{|l|}{ Primary outcome } \\
\hline \multirow[t]{5}{*}{ Mean change from baseline in viral load at day 11} & & -3.47 & \\
\hline & $700 \mathrm{mg},-3.67$ & & $-0.20(-0.66$ to 0.25$)$ \\
\hline & $2800 \mathrm{mg},-4.00$ & & $-0.53(-0.98$ to -0.08$)$ \\
\hline & $7000 \mathrm{mg},-3.38$ & & 0.09 (-0.37 to 0.55$)$ \\
\hline & Pooled doses, -3.70 & & $-0.22(-0.60$ to 0.15$)$ \\
\hline \multicolumn{4}{|l|}{ Secondary outcomes* } \\
\hline \multirow[t]{5}{*}{ Mean change from baseline in viral load at day 3} & & -0.85 & \\
\hline & $700 \mathrm{mg},-1.27$ & & $-0.42(-0.89$ to 0.06$)$ \\
\hline & $2800 \mathrm{mg},-1.50$ & & $-0.64(-1.11$ to -0.17$)$ \\
\hline & $7000 \mathrm{mg},-1.27$ & & $-0.42(-0.90$ to 0.06$)$ \\
\hline & Pooled doses, -1.35 & & $-0.49(-0.87$ to -0.11$)$ \\
\hline \multirow[t]{5}{*}{ Mean change from baseline in viral load at day 7} & & -2.56 & \\
\hline & $700 \mathrm{mg},-2.82$ & & $-0.25(-0.73$ to 0.23$)$ \\
\hline & $2800 \mathrm{mg},-3.01$ & & $-0.45(-0.92$ to 0.03$)$ \\
\hline & $7000 \mathrm{mg},-2.85$ & & $-0.28(-0.77$ to 0.20$)$ \\
\hline & Pooled doses, -2.90 & & $-0.33(-0.72$ to 0.06$)$ \\
\hline
\end{tabular}

Figure 9: Changes in viral load among patients [23]

\subsection{Convalescent Plasma Therapy (CPT)}

Convalescent Plasma is blood plasma taken from recovered Covid-19 patients. It may work as an antibody in affected Covid-19 patients to neutralize SARS-CoV-2 virus. In April, 2020 a study was conducted on 10 severe Covid-19 patients using CPT. After CP transfer symptoms like fever, cough, shortness of breath was improved within day 1 to 3 among those patients. Before 
CPT, three patients received mechanical ventilation, two received low-flow and three received high flow nasal cannula oxygenation. Reduction of pulmonary lesions were also detected on CT examinations. A risk of CPT is the transfer of potential pathogens. However, in the study, methylene blue photochemistry was used to reduce it [24].

\begin{tabular}{|c|c|c|c|c|c|}
\hline \multirow[b]{2}{*}{$\begin{array}{l}\text { Patient } \\
\text { no. }\end{array}$} & \multicolumn{3}{|c|}{ Drugs administered } & \multicolumn{2}{|c|}{ Oxygen support } \\
\hline & Antiviral treatment & Antibiotic or antifungal treatment & $\begin{array}{l}\text { Corticosteroids } \\
\text { treatment }\end{array}$ & Before $\mathrm{CP}$ therapy & After $\mathrm{CP}$ therapy \\
\hline 1 & $\begin{array}{c}\text { Arbidol } 0.2 \mathrm{~g} \mathrm{q} 8 \mathrm{~h} \text { po.Ribavirin } 0.5 \mathrm{~g} \\
\text { qd i.v. }\end{array}$ & Cefoperazone Sodium i.v. & None & $\begin{array}{l}\text { High-flow nasal cannula, } \\
\text { mechanical ventilation }\end{array}$ & Mechanical ventilation \\
\hline 2 & Arbidol $0.2 \mathrm{~g} \mathrm{q} 8 \mathrm{~h}$ po. & Cefoperazone Sodium i.v. & None & None & None \\
\hline 3 & Arbidol $0.2 \mathrm{~g} \mathrm{q} 8 \mathrm{~h} \mathrm{po}$ & Moxifloxacin i.v. & $\begin{array}{l}\text { Methylprednisolone } \\
\text { i.v. }\end{array}$ & $\begin{array}{l}\text { High-flow nasal cannula, } \\
\text { mechanical ventilation }\end{array}$ & High-flow nasal cannula \\
\hline 4 & Ribavirin $0.5 \mathrm{~g}$ qd i.v. & $\begin{array}{l}\text { Linezolid i.v. Imipenem-Sitastatin } \\
\text { Sodium i.v. }\end{array}$ & $\begin{array}{l}\text { Methylprednisolone } \\
\text { i.v. }\end{array}$ & Mechanical ventilation & High-flow nasal cannula \\
\hline \multirow[t]{3}{*}{5} & Arbidol $0.2 \mathrm{~g} \mathrm{qSh} \mathrm{po.}$ & Moxifloxacin i.v. & $\begin{array}{l}\text { Methylprednisolone } \\
\text { i.v. }\end{array}$ & Low-flow nasal cannula & Low-flow nasal cannula \\
\hline & Remdesivir $0.2 \mathrm{~g}$ qd i.v. & $\begin{array}{l}\text { Cefoperagone Sodium and } \\
\text { Tazobactam Sodium i.v. }\end{array}$ & & & \\
\hline & IFN-a $500 \mathrm{MIU}$ qd inh. & & & & \\
\hline 6 & Arbidol $0.2 \mathrm{~g} \mathrm{q} 8 \mathrm{~h}$ po. & $\begin{array}{l}\text { Cefoperazone Sodium } \\
\text { i.v.Levofloxacin i.v. }\end{array}$ & $\begin{array}{l}\text { Methylprednisolone } \\
\text { i.v. }\end{array}$ & High-flow nasal cannula & High-flow nasal cannula \\
\hline 7 & Arbidol $0.2 \mathrm{~g} \mathrm{q} 8 \mathrm{~h}$ po. & $\begin{array}{l}\text { Cefoperagone Sodium and } \\
\text { Tazobactam Sodium i.v. } \\
\text { Fluconazole i.v. }\end{array}$ & $\begin{array}{l}\text { Methylprednisolone } \\
\text { i.v. }\end{array}$ & High-flow nasal cannula & None \\
\hline 8 & $\begin{array}{l}\text { Arbidol } 0.2 \mathrm{~g} \mathrm{q} 8 \mathrm{~h} \text { po. } \\
\text { Ribavirin } 0.5 \mathrm{~g} \text { gd i.v. }\end{array}$ & None & None & None & None \\
\hline 9 & $\begin{array}{c}\text { Arbidol } 0.2 \mathrm{~g} \mathrm{q} 8 \mathrm{~h} \text { po. Oseltamivir } 75 \\
\text { mg q } 12 \mathrm{~h} \text { po. }\end{array}$ & None & None & Low-flow nasal cannula & $\begin{array}{c}\text { Low-flow nasal cannula } \\
\text { (Intermittent) }\end{array}$ \\
\hline & Peramivir $0.3 \mathrm{~g}$ qd i.v. & & & & \\
\hline 10 & $\begin{array}{c}\text { Arbidol } 0.2 \mathrm{~g} \mathrm{q} 8 \mathrm{~h} \text { po.IFN-a } 500 \\
\text { MIU qd inh. }\end{array}$ & $\begin{array}{l}\text { Cefoperazone Sodium } \\
\text { i.v.Caspofungin i.v. }\end{array}$ & $\begin{array}{l}\text { Methylprednisolone } \\
\text { i.v. }\end{array}$ & High-flow nasal cannula & High-flow nasal cannula \\
\hline
\end{tabular}

Figure 10: $\mathrm{CP}$ treatment results among patients [24]

However, in a recent study CPT did show any significant improvement among patients with severe Covid-19. Additionally, it was unclear from the trail whether earlier CPT treatment could have had improvement in the patients [25].

\section{Cell Therapy}

\subsection{Mesenchymal Stem Cell (MSC) Therapy}

MSC therapy is more preferable over other therapeutic strategies because it is free of ethical and social issues. They are also low invasive in nature and can be easily obtained from adipose tissue, bone marrow, umbilical cord. Covid-19 can trigger an immune overreaction called cytokine storm which produces large number of inflammatory factors in the immune system. 
This is where MSC therapy can come into play. MSC therapy has the potential to reduce the cytokine storm in COVID-19 patients. It can prevent lung tissue death by its immunomodulatory properties [26]. A study conducted in July, 2020 on a 65 -year old woman using human umbilical mesenchymal stem cells showed promising results in her improvement from COVID-19. Comparing CT images from day 2 to day 25, it was reported that her pulmonary inflammatory reaction was reduced. On day 21, her vital sign showed normal. On day 21 and 23 her COVID19 test was negative and on day 30 she was discharged from the hospital [27].
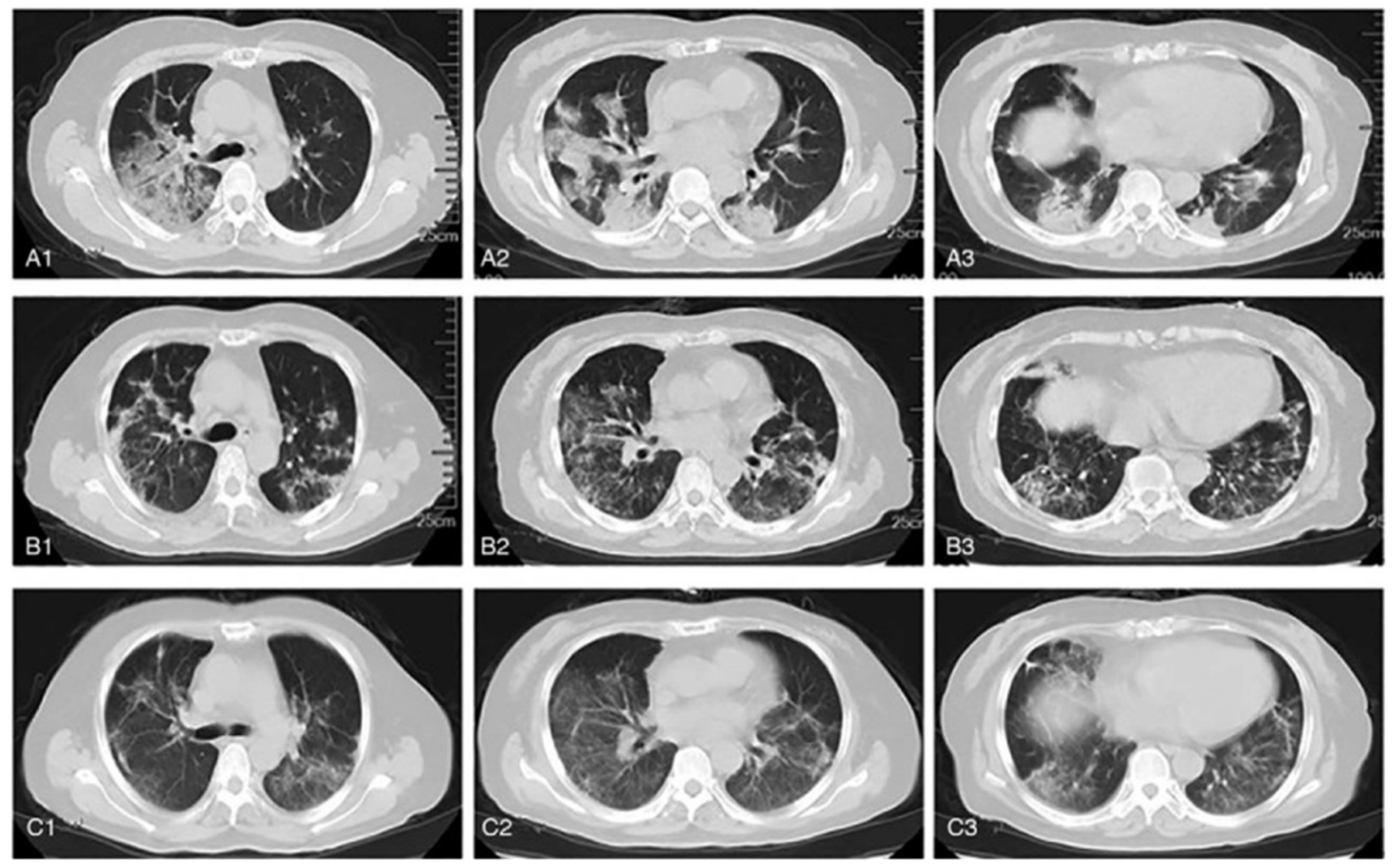

Figure 11: A1-A3= Day 2 CT Image, B1-B3= Day 20 CT Image, C1-C3= Day 25 CT Image.[27]

\section{Current Vaccine Stage}

As of November, 2020, 47 candidate vaccines in clinical evaluation, 155 candidate vaccines are in preclinical evaluation, according to World Health Organization protocol. Among those some of the vaccine candidates are already in phase 3 of clinical trials.

\section{Conclusion and Future Work}

Covid-19 is a rapidly emerging crisis. Despite having a large amount of available treatment, there is no definitive treatment that can cure COVID-19. Current studies have its own limitations which are being addressed in the literature. Most of the limitations were within the context of a patient, their health concern, pre-existing disease, sample size etc. Despite having gaps among those issues, many treatments show promising results which need further research and development to better understand the efficacy of a treatment. Even though clinical trials of 
vaccines are still in the process, only time will tell how fast a safe vaccine can be accessible to the people.

\section{Acknowledgments}

I would like to thank Dr. Sona Vasudevan, Professor in the Department of Biochemistry and Molecular Biology at Georgetown University, to help me explore the virology of Covid-19 in her summer program. 


\section{References}

[1] Vellas, C et al. "COVID-19, Virology and Geroscience: A Perspective." The journal of nutrition, health \& aging vol. 24,7 (2020): 685-691. doi:10.1007/s12603-020-1416-2

[2] Fehr, Anthony R et al. "Middle East Respiratory Syndrome: Emergence of a Pathogenic Human Coronavirus." Annual review of medicine vol. 68 (2017): 387-399. doi:10.1146/annurevmed-051215-031152

[3]Chafekar, Aasiyah, and Burtram C Fielding. "MERS-CoV: Understanding the Latest Human Coronavirus Threat.” Viruses vol. 10,2 93. 24 Feb. 2018, doi:10.3390/v10020093

[4]Zhong, N S et al. "Epidemiology and cause of severe acute respiratory syndrome (SARS) in Guangdong, People's Republic of China, in February, 2003." Lancet (London, England) vol. 362,9393 (2003): 1353-8. doi:10.1016/s0140-6736(03)14630-2

[5]Wu, Fan et al. "A new coronavirus associated with human respiratory disease in China."

Nature vol. 579,7798 (2020): 265-269. doi:10.1038/s41586-020-2008-3

[6]Cui, Jie et al. "Origin and evolution of pathogenic coronaviruses." Nature reviews.

Microbiology vol. 17,3 (2019): 181-192. doi:10.1038/s41579-018-0118-9

[7]Mueller, Amber L et al. "Why does COVID-19 disproportionately affect older people?."

Aging vol. 12,10 (2020): 9959-9981. doi:10.18632/aging.103344

[8]Chengyuan Liang, et al. "A promising antiviral candidate drug for the COVID-19 pandemic: A mini-review of remdesivir", European Journal of Medicinal Chemistry, Volume 201,2020,112527, ISSN 0223-5234, https://doi.org/10.1016/j.ejmech.2020.112527.

[9]Pasquini, Zeno et al. "Effectiveness of remdesivir in patients with COVID-19 under mechanical ventilation in an Italian ICU." The Journal of antimicrobial chemotherapy vol. 75,11 (2020): 3359-3365. doi:10.1093/jac/dkaa321

[10]Beigel, John et al. "Remdesivir for the Treatment of Covid-19-Final Report." The New England Journal of Medicine, Nov 5, 2020. doi:10.1056/NEJMoa2007764.

[11]Geleris, Joshua et al. "Observational Study of Hydroxychloroquine in Hospitalized Patients with Covid-19.” The New England Journal of Medicine, June 18, 2020.

doi:10.1056/NEJMoa2012410

[12]Cao, Bin et al. "A Trial of Lopinavir-Ritonavir in Adults Hospitalized with Severe Covid19." The New England journal of medicine vol. 382,19 (2020): 1787-1799.

doi:10.1056/NEJMoa2001282

[13]Heidary, Fatemeh, and Reza Gharebaghi. "Ivermectin: a systematic review from antiviral effects to COVID-19 complementary regimen." The Journal of antibiotics vol. 73,9 (2020): 593 602. doi:10.1038/s41429-020-0336-Z

[14]Leon Caly et al. "The FDA-approved drug ivermectin inhibits the replication of SARS-CoV2 in vitro." Antiviral Research, Volume 178, 2020, 104787, ISSN 0166-3542, https://doi.org/10.1016/j.antiviral.2020.104787.

[15]Lisa Oestereich et al. "Successful treatment of advanced Ebola virus infection with T-705 (favipiravir) in a small animal model”, Antiviral Research, Volume 105, 2014, Pages 17-21, ISSN 0166-3542, https://doi.org/10.1016/j.antiviral.2014.02.014. 
[16]Wang, Manli et al. "Remdesivir and chloroquine effectively inhibit the recently emerged novel coronavirus (2019-nCoV) in vitro." Cell research vol. 30,3 (2020): 269-271.

doi:10.1038/s41422-020-0282-0

[17]Cai, Qingxian et al. "Experimental Treatment with Favipiravir for COVID-19: An OpenLabel Control Study." Engineering (Beijing, China), 10.1016/j.eng.2020.03.007. 18 Mar. 2020, doi:10.1016/j.eng.2020.03.007

[18]National Center for Biotechnology Information. "PubChem Compound Summary for CID 37542, Ribavirin" PubChem, https://pubchem.ncbi.nlm.nih.gov/compound/Ribavirin. Accessed 12 November, 2020.

[19]Tong, Song et al. "Ribavirin therapy for severe COVID-19: a retrospective cohort study." International journal of antimicrobial agents vol. 56,3 (2020): 106114.

doi:10.1016/j.ijantimicag.2020.106114

[20]Ortolani, Claudio, and Elide A Pastorello. "Hydroxychloroquine and dexamethasone in COVID-19: who won and who lost?." Clinical and molecular allergy : CMA vol. 18 17. 9 Sep. 2020, doi:10.1186/s12948-020-00132-7

[21]RECOVERY Collaborative Group et al. "Dexamethasone in Hospitalized Patients with Covid-19 - Preliminary Report." The New England journal of medicine, NEJMoa2021436. 17 Jul. 2020, doi:10.1056/NEJMoa2021436

[22]Clementi, Nicola et al. "Interferon- $\beta$-1a Inhibition of Severe Acute Respiratory SyndromeCoronavirus 2 In Vitro When Administered After Virus Infection.” The Journal of infectious diseases vol. 222,5 (2020): 722-725. doi:10.1093/infdis/jiaa350

[23]Chen, Peter et al. "SARS-CoV-2 Neutralizing Antibody LY-CoV555 in Outpatients with Covid-19." The New England Journal of Medicine, Oct 28, 2020.DOI:

10.1056/NEJMoa2029849

[24]Duan, Kai et al. "Effectiveness of convalescent plasma therapy in severe COVID-19 patients." Proceedings of the National Academy of Sciences of the United States of America vol. 117,17 (2020): 9490-9496. doi:10.1073/pnas.2004168117

[25]Li, Ling et al. "Effect of Convalescent Plasma Therapy on Time to Clinical Improvement in Patients With Severe and Life-threatening COVID-19: A Randomized Clinical Trial." JAMA vol. 324,5 (2020): 460-470. doi:10.1001/jama.2020.10044

[26]Golchin, Ali et al. "Mesenchymal Stem Cell Therapy for COVID-19: Present or Future." Stem cell reviews and reports vol. 16,3 (2020): 427-433. doi:10.1007/s12015-020-09973-w [27]Liang, Bing et al. "Clinical remission of a critically ill COVID-19 patient treated by human umbilical cord mesenchymal stem cells: A case report.” Medicine vol. 99,31 (2020): e21429. doi:10.1097/MD.0000000000021429

[28]Davoudi-Monfared, Effat et al. "A Randomized Clinical Trial of the Efficacy and Safety of Interferon $\beta$-1a in Treatment of Severe COVID-19." Antimicrobial agents and chemotherapy vol. 64,9 e01061-20. 20 Aug. 2020, doi:10.1128/AAC.01061-20 